\title{
Prevalence of eyelid diseases among adults in Hong Kong
}

Shiu Ting Mak', FRCSEd(Ophth), Sze Wai Jeremy John Kwok ${ }^{2}$, FHKAM(Ophthalmology), Hunter KL Yuen ${ }^{3,4}$, FRCOphth, FRCS(Ed)

${ }^{1}$ Department of Ophthalmology, United Christian Hospital, Hong Kong

${ }^{2}$ Department of Ophthalmology, Grantham Hospital, Hong Kong

${ }^{3}$ Hong Kong Eye Hospital, Hong Kong

${ }^{4}$ Department of Ophthalmology and Visual Sciences, The Chinese University of Hong Kong

Correspondence and reprint requests:

Dr Shiu Ting Mak, Department of Ophthalmology, United Christian Hospital, 130 Hip Wo Street, Kwun Tong, Kowloon, Hong Kong.

Email:dr.makst@gmail.com

\section{Abstract}

Introduction: Eyelid diseases affect visual function and quality of life. This is the first study to investigate the prevalence of eyelid diseases among the general population in Hong Kong.

Methods: On 22 October 2017, The College of Ophthalmologists of Hong Kong and The Hong Kong Ophthalmological Society jointly organized a Public Education Day. A total of 165 participants were recruited for eyelid disease screening. Eyelid examination was performed by ophthalmology residents under the supervision of a specialist subspecializing in oculoplastics to identify any eyelid diseases (dermatochalasis, ptosis, entropion, ectropion, lash misdirection, presence of eyelid masses, and blepharitis). The prevalence of these eyelid diseases and their association with age and sex were determined.

Results: The 165 participants (122 females and 43 males) were all Chinese and were aged 24 to 92 (mean, 68 ) years; $23.6 \%$ were $<60$ years old, $62.4 \%$ were 60 80 years old, and $13.9 \%$ were $>80$ years old. The most common eyelid disease was dermatochalasis, with a prevalence of $61.8 \%$, followed by blepharitis $(32.1 \%)$, ptosis $(7.3 \%)$, and eyelid mass $(6.7 \%)$. Lash misdirection, entropion, and ectropion were uncommon, with a prevalence of $2.4 \%, 0.6 \%$, and $0 \%$, respectively. Dermatochalasis was more common with increasing age. Other eyelid diseases did not correlate with age.

Conclusion: Eyelid diseases are not uncommon among the general population in Hong Kong, particularly dermatochalasis, ptosis, and blepharitis. Eyelid diseases may negatively impact patients functionally and psychosocially. Clinicians and the general public should be aware of these eyelid diseases.

Key words: Blepharitis; Ectropion; Entropion; Eyelid diseases; Eyelid neoplasms

\section{Introduction}

Common eyelid diseases include dermatochalasis, ptosis, entropion, ectropion, lash misdirection, presence of eyelid masses, and blepharitis (Figures 1 and 2). Eyelid diseases may affect visual function and quality of life. Correction of eyelid diseases significantly improves vision-related quality of life..$^{1-4}$

In Australia, the Blue Mountains Eye Study reported that $3.9 \%$ of the study population had ectropion. ${ }^{5}$ In Brazil, the prevalence of involutional entropion and ectropion in the elderly population was $2.1 \%$ and $2.9 \%$, respectively. ${ }^{6}$ In Manchester, England, the prevalence of ptosis was as high as $11.5 \%$ in the aged population. Similar studies have not been conducted in Hong Kong.

Many eyelid diseases are involutional in nature. The prevalence of eyelid diseases increases in an ageing population. This may increase the public healthcare burden. This study aimed to determine the prevalence of eyelid diseases among the adult population in Hong Kong, and to determine the association of eyelid diseases with age and sex. 


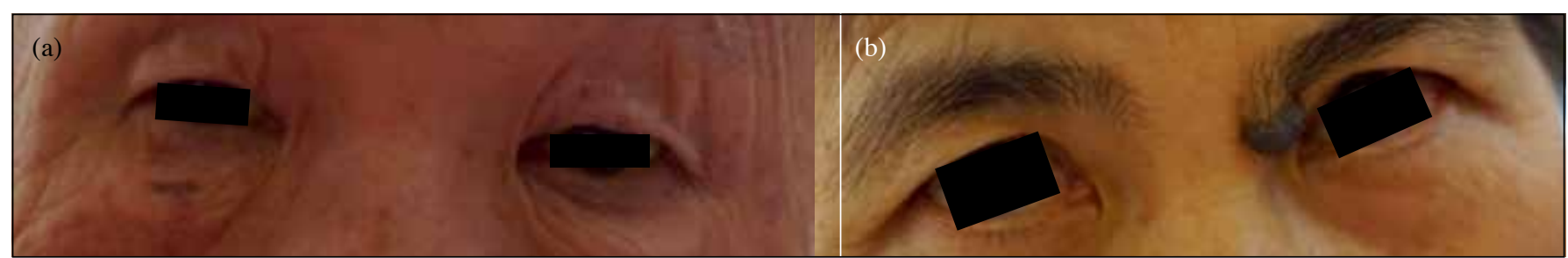

Figure 1. Clinical photographs showing (a) bilateral upper eyelid dermatochalasis and (b) a mass on the left upper eyelid.

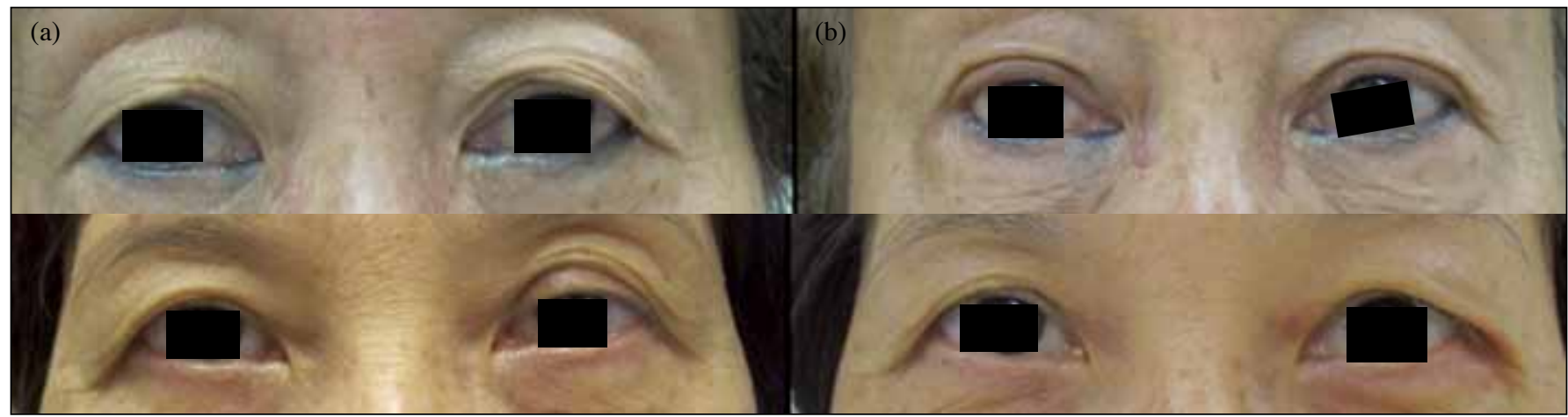

Figure 2. Clinical photographs before and after (a) blepharoplasty and (b) ptosis correction.

\section{Methods}

This cross-sectional study was approved by the Kowloon Central / Kowloon East Cluster Research Ethics Committee of the Hospital Authority (ref: KC/KE-18-0153-ER-4). On 22 October 2017, The College of Ophthalmologists of Hong Kong and The Hong Kong Ophthalmological Society jointly organized a Public Education Day (comprising health talks and eyelid disease screening) in a shopping mall in Tsuen Wan, New Territories, Hong Kong. A total of 165 participants were recruited for eyelid disease screening; about half were through the Hong Kong Association of Senior Citizens and the remaining by phone upon reading a recruitment advertisement in the Sky Post, a free newspaper. There was no age limit or sex restriction to participation.

Eyelid examination was performed by ophthalmology residents under the supervision of a specialist subspecializing in oculoplastics to identify any eyelid diseases (dermatochalasis, ptosis, entropion, ectropion, lash misdirection, presence of eyelid masses, and blepharitis). Dermatochalasis was defined as excessive eyelid skin on the upper eyelid hanging over the eyelashes. ${ }^{7}$ Ptosis was defined as eyes with palpebral fissure height of $<9 \mathrm{~mm}$, or $\geq 2 \mathrm{~mm}$ difference between two eyelids. ${ }^{8}$ Ectropion was defined as everted lower eyelid, whereas entropion as inverted eyelids. Lash misdirection can occur diffusely across the entire lid or in a small segmental distribution. Eyelid masses can occur anywhere in the upper or lower eyelids. Blepharitis was characterized by chronic inflammation of the eyelid, usually at the base of the eyelashes, with inflamed and reddened eyelids.
The prevalence of these eyelid diseases was determined. Association of these eyelid diseases with age and sex was determined using Chi-squared test. Statistical analysis was performed using the Statistical Package for the Social Sciences version 18.0 (SPSS, Chicago [IL], USA). A p value of $<0.05$ was considered statistically significant.

\section{Results}

The 165 participants (122 females and 43 males) were all Chinese and were aged 24 to 92 (mean, 68; standard deviation, 13 ) years; $23.6 \%$ were $<60$ years old, $62.4 \%$ were 60-80 years old, and $13.9 \%$ were $>80$ years old (Table).

The most common eyelid disease was dermatochalasis, with a prevalence of $61.8 \%(n=102)$. It occurred more commonly with increasing age, with prevalence of $25.6 \%$, $71.8 \%$, and $78.3 \%$ in the age-groups of $<60$ years, $60-80$ years, and $>80$ years, respectively $(\mathrm{p}<0.001)$. The prevalence was comparable in males and females $(58.1 \%$ vs. $63.1 \%$, $\mathrm{p}=0.56)$.

Blepharitis was identified in 53 participants, giving a prevalence of $32.1 \%$. The prevalence was not associated with age: $25.6 \%, 37.9 \%$, and $17.4 \%$, in the age-groups of $<60$ years, $60-80$ years, and $>80$ years, respectively $(\mathrm{p}=0.10)$, and was comparable in males and females $(34.9 \%$ vs. $31.1 \%$, $\mathrm{p}=0.65$ ).

Ptosis was identified in 12 participants, giving a prevalence of $7.3 \%$. It occurred more commonly in males than females ( $18.6 \%$ vs. $3.3 \%, p=0.01)$. It occurred most commonly in 


\section{ORIGINAL ARTICLE}

\begin{tabular}{|c|c|c|c|c|c|c|c|}
\hline \multirow[t]{2}{*}{ Parameter } & \multicolumn{7}{|c|}{ Prevalence (\%) } \\
\hline & Dermatochalasis & Ptosis & Entropion & Ectropion & Lash misdirection & Eyelid mass & Blepharitis \\
\hline Overall (n=165) & 61.8 & 7.3 & 0.6 & 0 & 2.4 & 6.7 & 32.1 \\
\hline \multicolumn{8}{|l|}{ Sex } \\
\hline Male $(n=43)$ & 58.1 & 18.6 & 0 & 0 & 2.3 & 9.3 & 34.9 \\
\hline Female $(n=122)$ & 63.1 & 3.3 & 0.8 & 0 & 2.5 & 5.7 & 31.1 \\
\hline \multicolumn{8}{|l|}{ Age-group, y } \\
\hline$<60(\mathrm{n}=39)$ & 25.6 & 10.3 & 0 & 0 & 5.1 & 7.7 & 25.6 \\
\hline $60-80(n=103)$ & 71.8 & 5.8 & 1.0 & 0 & 1.0 & 4.9 & 37.9 \\
\hline$>80(\mathrm{n}=23)$ & 78.3 & 8.7 & 0 & 0 & 4.3 & 13.0 & 17.4 \\
\hline
\end{tabular}

those aged $<60$ years $(10.3 \%)$, followed by those aged $>80$ years $(8.7 \%)$ and $60-80$ years $(5.8 \%)$ [p=0.64].

Eyelid masses were identified in 11 participants, giving a prevalence of $6.7 \%$. They occurred most commonly in those aged $>80$ years $(13.0 \%)$, followed by those aged $<60$ years $(7.7 \%)$ and $60-80$ years $(4.9 \%)$ [p=0.34]. The prevalence in males and females was $9.3 \%$ and $5.7 \%$, respectively $(\mathrm{p}=0.42)$.

Lash misdirection, entropion, and ectropion were uncommon, with a prevalence of $2.4 \%, 0.6 \%$, and $0 \%$, respectively.

\section{Discussion}

In our study, the prevalence of dermatochalasis was $61.8 \%$, which is higher than the $17.8 \%$ reported in a Rotterdam study of 5578 people. ${ }^{9}$ Dermatochalasis occurred more commonly with increasing age and is a feature of the aging process of the skin. ${ }^{10}$ Male sex is a risk factor. ${ }^{7}$ In our study, the prevalence of dermatochalasis was similar between males and females $(58.1 \%$ vs $63.1 \%, \mathrm{p}=0.56)$.

Dermatochalasis and ptosis have a negative impact on function and psychosociology. ${ }^{11,12}$ Functionally, patients may experience superior visual field loss, impaired reading and other close-work ability owing to down-gaze ptosis, a chin-up backward head tilt owing to visual axis obscuration, symptoms of discomfort or eye strain owing to droopy lids, and in severe cases, interference with central visual owing to upper eyelid position..$^{11}$ Psychosocially, patients with blepharoptosis or dermatochalasis are viewed negatively. ${ }^{12}$ Ptosis correction and blepharoplasty significantly improve vision-related quality of life, ${ }^{1-4}$ with good functional and cosmetic outcome.

In our study, the prevalence of dermatochalasis and ptosis was $61.8 \%$ and $7.3 \%$, respectively. The conditions may be undiagnosed in a large proportion of the population. Clinicians should proactively identify such patients and refer them to an ophthalmologist for further management. In our study, the prevalence of eyelid mass was $6.7 \%$. Eyelid masses can be benign or malignant. In a review from Korea, approximately $36 \%$ of all eyelid tumors were malignant. ${ }^{13}$ The incidence of malignant eyelid tumors has increased worldwide. ${ }^{14-16}$ This trend was also reported in a local study, with the incidence increased from 0.6 per million people in 1997 to 2.3 per million people in $2009 .{ }^{17}$ Biopsy should be performed to confirm the nature of the lesions. In our study, the prevalence of blepharitis was $32.1 \%$. In a Korean study of the epidemiology of blepharitis in a large populationbased sample, the prevalence was $8.1 \%$ among subjects aged $\geq 40$ years. ${ }^{18}$ Although blepharitis is often self-limiting, it can be severe or chronic and leads to lid malposition such as ectropion, keratitis, or corneal ulceration with consequent vision loss. ${ }^{19}$ A Taiwan study reported that patients with blepharitis were at higher risk of developing anxiety and depression..$^{20}$ Blepharitis is associated with dysfunctional tear production or dry eyes and meibomian gland dysfunction. Ophthalmologist awareness of such conditions has increased since the publication of diagnosis and treatment guidelines for such disorders. ${ }^{21}$ Clinical improvement can be achieved with simple measures such as cleaning the lid with diluted baby shampoo..$^{22}$ Other effective treatments include tear supplements and lubricants, various types of drugs, and nutritional supplements. ${ }^{21}$ Given the high prevalence of blepharitis among the local population, more education should be provided to enable early identification of the disease to prevent possible complications and reduce the public healthcare burden.

Eyelid diseases can also affect other parts of the eye and body. For instance, untreated entropion can cause corneal abrasion, microbial keratitis, corneal vascularization, and subsequently vision loss. ${ }^{23}$ Trachoma may cause lash misdirection and remains a leading infectious cause of blindness according to the World Health Organization. ${ }^{24}$ Malignant eyelid masses, apart from being locally invasive, may result in lymph node metastasis, systemic metastasis, and even death. ${ }^{25}$ These examples highlight the importance of eyelid health. Clinicians should refer patients with eyelid diseases to ophthalmologists for further assessment. Patients with complicated eyelid diseases should be managed by 
oculoplastic subspecialists who are dedicated to eyelid, lacrimal, and orbital care. ${ }^{26}$

Our study has limitations. Recruitment of participants for screening was non-randomized, and hence there may have been selection bias. All participants were Chinese and therefore the results may not be directly comparable or applicable to other ethnic populations.

\section{Conclusion}

Eyelid diseases are not uncommon among the general population in Hong Kong, particularly dermatochalasis, ptosis, and blepharitis. Eyelid diseases may negatively impact patients functionally and psychosocially. Both clinicians and the general public should be aware of these eyelid diseases.

\section{Acknowledgement}

The authors would like to thank The College of Ophthalmologists of Hong Kong and the Hong Kong Ophthalmological Society for organizing the Public Education Day 2017. The authors would also like to thank all voluntary ophthalmology residents and medical students for their help.

\section{Declaration}

The authors have no conflicts of interest to disclose.

\section{References}

1. Battu VK, Meyer DR, Wobig JL. Improvement in subjective visual function and quality of life outcome measures after blepharoptosis surgery. Am J Ophthalmol 1996;121:677-86.

2. Federici TJ, Meyer DR, Lininger LL. Correlation of the visionrelated functional impairment associated with blepharoptosis and the impact of blepharoptosis surgery. Ophthalmology 1999;106:1705-12.

3. Warwar RE, Bullock JD, Markert RJ, Marciniszyn SL, Bienenfeld DG. Social implications of blepharoptosis and dermatochalasis. Ophthalmic Plast Reconstr Surg 2001;17:234-40.

4. Smith HB, Jyothi SB, Mahroo OA, et al. Patient-reported benefit from oculoplastic surgery. Eye (Lond) 2012;26:141823.

5. Mitchell P, Hinchcliffe P, Wang JJ, Rochtchina E, Foran $S$. Prevalence and associations with ectropion in an older population: the Blue Mountains Eye Study. Clin Exp Ophthalmol 2001;29:108-10.

6. Damasceno RW, Osaki MH, Dantas PE, Belfort $R \mathrm{Jr}$. Involutional entropion and ectropion of the lower eyelid: prevalence and associated risk factors in the elderly population. Ophthal Plast Reconstr Surg 2011;27:317-20.

7. Jacobs LC, Liu F, Bleyen I, et al. Intrinsic and extrinsic risk factors for sagging eyelids. JAMA Dermatol 2014;150:83643.

8. Şahlı E, Hoşal BM, Zilelioğlu G, Dinçer N, Tezel GG. The role of apoptosis in blepharoptosis. Eye (Lond) 2013;27:823-7.

9. Hofman A, Darwish Murad S, van Duijn CM, et al. The Rotterdam Study: 2014 objectives and design update. Eur J Epidemiol 2013;28:889-926.

10. Guinot C, Malvy DJ, Ambroisine L, et al. Relative contribution of intrinsic vs extrinsic factors to skin aging as determined by a validated skin age score. Arch Dermatol 2002;138:1454-60.

11. Bullock JD, Warwar RE, Bienenfeld DG, Marciniszyn SL, Markert RJ. Psychosocial implications of blepharoptosis and dermatochalasis. Trans Am Ophthalmol Soc 2001;99:65-72.

12. Cahill KV, Bradley EA, Meyer DR, et al. Functional indications for upper eyelid ptosis and blepharoplasty surgery: a report by the American Academy of Ophthalmology.
Ophthalmology 2011;118:2510-7.

13. Roh KK, Lee JH, Youn DH. Clinical analysis of tumors of the eye and its adnexa. Korean J Ophthalmol 1988;2:27-31.

14. Lee SB, Saw SM, Au Eong KG, et al. Incidence of eyelid cancers in Singapore from 1968 to 1995. Br J Ophthalmol 1999;83:595-7.

15. Paavilainen V, Tuominen J, Pukkala E, Saari KM. Basal cell carcinoma of the eyelid in Finland during 1953-97. Acta Ophthalmol Scand 2005;83:215-20.

16. Lin HY, Cheng CY, Hsu WM, Kao WH, Chou P. Incidence of eyelid cancers in Taiwan: a 21-year review. Ophthalmology 2006;113:2101-7.

17. Mak ST, Wong AC, Io IY, Tse RK. Malignant eyelid tumors in Hong Kong 1997-2009. Jpn J Ophthalmol 2011;55:681-5.

18. Rim TH, Kang MJ, Choi M, Seo KY, Kim SS. Ten-year incidence and prevalence of clinically diagnosed blepharitis in South Korea: a nationwide population-based cohort study. Clin Exp Ophthalmol 2017;45:448-54.

19. Smolin G, Okumoto M. Staphylococcal blepharitis. Arch Ophthalmol 1977;95:812-6.

20. Chiang CC, Lin CL, Tsai YY, Peng CL, Liao YT, Sung FC. Patients with blepharitis are at elevated risk of anxiety and depression. PLoS One 2013;8:e83335.

21. Milner MS, Beckman KA, Luchs JI, et al. Dysfunctional tear syndrome: dry eye disease and associated tear film disorders - new strategies for diagnosis and treatment. Curr Opin Ophthalmol 2017;27(Suppl 1):3-47.

22. Sung J, Wang MTM, Lee SH, et al. Randomized doublemasked trial of eyelid cleansing treatments for blepharitis. Ocul Surf 2018;16:77-83.

23. Pereira $M G$, Rodrigues MA, Rodrigues SA. Eyelid entropion. Semin Ophthalmol 2010;25:52-8.

24. Burton M, Habtamu E, Ho D, Gower EW. Interventions for trachoma trichiasis. Cochrane Database Syst Rev 2015;11:CD004008.

25. Kaliki S, Ayyar A, Dave TV, Ali MJ, Mishra DK, Naik MN. Sebaceous gland carcinoma of the eyelid: clinicopathological features and outcome in Asian Indians. Eye (Lond) 2015;29:958-63.

26. Saleh GM, Athanasiadis I, Collin JR. Training and oculoplastics: past, present and future. Orbit 2013;32:111-6. 